\title{
STUDI POTENSI PEMBANGKIT LISTRIK TENAGA MIKRO (PLTMH) DENGAN MENGGUNAKAN APLIKASI HYDROPOWER CASIMIR DI SUNGAI NOLING KELURAHAN NOLING KABUPATEN LUWU
}

\author{
Haerun $^{1}$, Al Imran ${ }^{2}$, Riana T Mangesa ${ }^{3}$ \\ ${ }^{1}$ Pendidikan Teknik Elektro Universitas Negeri Makassar \\ haerun.s726@gmail.com \\ ${ }^{2}$ Pendidikan Teknik Elektro Universitas Negeri Makassar \\ alimran231@gmail.com \\ ${ }^{3}$ Pendidikan Teknik Elektro Universitas Negeri Makassar \\ rianamangesa@yahoo.com
}

\begin{abstract}
ABSTRAK
Tujuan penelitian ini adalah; 1) mengetahui debit air dan head (tinggi jatuh air) di Sungai Noling Kelurahan Noling Kabupaten Luwu, 2) mengetahui jenis turbin yang sesuai untuk pembangkit listrik tenaga mikro hidro (PLTMH) ditinjau dari debit air dan head (tinggi jatuh air) di Sungai Noling Kelurahan Noling Kabupaten Luwu, dan 3) mengetahui potensi daya listrik yang bisa dihasilkan dari pembangkit listrik tenaga mikro hidro (PLTMH) menggunakan aplikasi Hydropower Casimir. Teknik pengumpulan data dilakukan dengan observasi lapangan, melalui wawancara langsung serta dokumentasi. Teknik analisis data yang digunakan adalah analisis statistik deskriptif berupa penggunaan data statistik dari dinas terkait dan analisis menggunakan aplikasi hydropower casimir. Hasil penelitian ini adalah; (1) debit air rata-rata per tahun adalah $\mathrm{Q}_{2015}=21,82 \mathrm{~m}^{3} / \mathrm{s}, \mathrm{Q}_{2016}=41,62 \mathrm{~m}^{3} / \mathrm{s}, \mathrm{Q}_{2017}=46,61 \mathrm{~m}^{3} / \mathrm{s}, \mathrm{Q}_{2018}=20,18 \mathrm{~m}^{3} / \mathrm{s}, \mathrm{Q}_{2019}=19 \mathrm{~m}^{3} / \mathrm{s}$ dan head (konstan) $=2,17 \mathrm{~m},(2)$ jenis turbin yang digunakan untuk pembangkit listrik tenaga mikro hidro (PLTMH) ditinjau dari debit air dan head (tinggi jatuh air) adalah jenis turbin kaplan, (3) potensi daya listrik tahunan yang bisa dihasilkan dari pembangkit listrik tenaga mikro hidro (PLTMH) dengan menggunakan aplikasi hydropower casimir adalah $\mathrm{P}_{2015}=361,91 \mathrm{~kW}, \mathrm{P}_{2016}=712,38 \mathrm{~kW}, \mathrm{P}_{2017}=778,81 \mathrm{~kW}, \mathrm{P}_{2018}=334,33$ $\mathrm{kW}, \mathrm{P}_{2019}=314,48 \mathrm{~kW}$ dan rekapitulasi potensi daya listrik rata-rata 5 tahun terakhir rentang tahun 20152019 adalah sebesar 500,38 kW.
\end{abstract}

Kata Kunci: Debit Air, Head Air, Pembangkit Listrik Tenaga Mikro Hidro

\section{STUDY OF THE POTENTIAL OF MICRO POWER PLANT (PLTMH) BY USING THE CASIMIR HYDROPOWER APPLICATION AT NOLING RIVER, NOLING SUB- DISTRICT, LUWU REGENCY}

\begin{abstract}
The aims of this research are; 1) determine the water discharge and head (water fall height) in the Noling River, Noling Village, Luwu Regency, 2) determine the type of turbine that is suitable for micro hydro power plants (PLTMH) in terms of water discharge and head (water fall height) in Noling River, Noling Village, Luwu Regency, and 3) determine the potential for electrical power that can be generated from a micro hydro power plant (PLTMH) using the Hydropower Casimir. Data collection techniques were carried out by field observations, through direct interviews and documentation. The data analysis technique used is descriptive statistical analysis in the form of statistical data from the relevant agencies and analysis using the Casimir hydropower application. The results of this study are; (1) the average water discharge per year is $Q 2015=21.82 \mathrm{m3} / \mathrm{s}, Q 2016=41.62 \mathrm{~m} 3 / \mathrm{s}, Q 2017=46.61 \mathrm{m3} / \mathrm{s}, Q 2018=20.18 \mathrm{~m} 3 / \mathrm{s}, Q 2019=19 \mathrm{~m} 3 / \mathrm{s}$ and head (constant) $=2.17 \mathrm{~m}$, (2) the type of turbine used for micro hydro power plants (PLTMH) in terms of water discharge and head (water fall height) is a type of Kaplan turbine, (3) potential The annual electrical power that can be generated from micro hydro power plants (PLTMH) using the Casimir hydropower application is $P 2015=361.91 \mathrm{~kW}, P 2016=712.38 \mathrm{~kW}, P 2017=778.81 \mathrm{~kW}, P 2018=334.33$ $\mathrm{kW}, P 2019=314.48 \mathrm{~kW}$ and the recapitulation of the average electric power potential for the last 5 years in the 2015-2019 range is $500.38 \mathrm{~kW}$.
\end{abstract}

Keyword: Water Discharge, Water Head, Micro Hydro Power Plant 


\section{PENDAHULUAN}

Pertumbuhan penduduk dan industri yang terus meningkat mengakibatkan konsumsi energi listrik pun terus bertambah. Hal ini bertolak belakang dengan ketersediaan energi listrik yang sebagian besar berasal dari energi fosil, dimana produksi terhadap energi fosil semakin lama semakin menipis sedangkan energi fosil yang selama ini menjadi bahan bakar utama dalam pembangkitan energi listrik. Energi fosil ini sendiri adalah energi yang tidak dapat diperbaharui karena membutuhkan waktu yang sangat lama dalam pembentukannya. Ketenagalistrikan menyebutkan salah satu upaya pemerintah dalam pengembangan dan pengoptimalan potensi tenaga air adalah dengan memanfaatkan aliran sungai sebagai PLTMH [1].

Untuk memenuhi kebutuhan energi listrik yang terus meningkat sekaligus mendorong kegiatan ekonomi, pemerintah terus mengembangkan berbagai alternatif dan salah upaya pencarian sumber energi yang ramah lingkungan diantaranya energi terbarukan. Potensi energi terbarukan, seperti biomassa, panas bumi, surya, air, dan angin yang sampai saat ini mempunyai potensi sangat besar di Indonesia. Dengan mengubah pola pikir bahwa energi baru terbarukan (EBT) bukan sekedar sebagai energi alternatif dari bahan bakar fosil, tetapi harus menjadi pasokan energi nasional. Target bauran energi baru dan terbarukan dengan porsi EBT 23\% pada tahun 2025 dan di tahun 2050 paling sedikit sebesar $31 \%$ [2].

Mikro hidro atau biasa disebut dengan Pembangkit Listrik Tenaga Mikro Hidro (PLTMH) adalah suatu pembangkit listrik skala kecil yang menggunakan tenaga air sebagai tenaga penggeraknya seperti saluran irigasi, sungai atau air terjun alam dengan cara memanfaatkan tinggi terjunan (head) dan jumlah debit air [3].

Pembangkit Listrik Tenaga Mikro Hidro (PLTMH) sangat cocok dikembangkan di daerah pedesaan terpencil yang memiliki potensi sumber energi terbarukan seperti daerah-daerah yang memiliki ketersediaan air yang melimpah. Air merupakan salah satu sumber daya alam yang dapat diperbarui. Secara konstan tersedia melalui siklus global, penguapan dan pengembunan. Panas dari sinar matahari menyebabkan air danau dan air laut menguap membentuk awan, air kemudian jatuh kembali ke bumi melalui hujan dan mengalir ke sungai kemudian kembali ke laut [4].
Pada saat ini sumber daya potensi air disetiap daerah belum dapat dimanfaatkan secara optimal oleh masyarakat setempat khususnya pemerintah daerah provinsi maupun kabupaten. Hal ini disebabkan pemahaman mengenai tahapan yang harus dilakukan untuk membangun Pembangkit Listrik Tenaga Mikro Hidro (PLTMH) masih kurang, khususnya bagaimana melakukan studi potensi dan Detail Engineering Design (DED) belum dilakukan dengan benar dan tepat. Potensi pengembangan Pembangkit Listrik Tenaga Mikro Hidro (PLTMH) di Indonesia masih sangat terbuka.

\section{METODE PENELITIAN}

Jenis penelitian ini adalah penelitian kuantitatif. Penelitian kuantitatif adalah pendekatan ilmiah yang memandang suatu realitas itu dapat diklasifikasikan, konkrit, teramati dan terukur, hubungan variabelnya bersifat sebab akibat dimana data penelitiannya berupa angka-angka dan analisisnya menggunakan statistik [5].

Penelitian ini dilakukan di Sungai Noling Kelurahan Noling Kabupaten Luwu pada titik koordinat 03016'06 LS, 120 $10^{\circ} 58^{\prime \prime}$ BT. Pengumpulan data dalam penelitian ini, menggunakan observasi, wawancara dan dokumentasi. Data dianalisis menggunakan aplikasi hydropower Casimir untuk mengetahui potensi daya yang bisa dibangkitkan dari PLTMH.

\section{HASIL DAN PEMBAHASAN}

\section{A. Hasil Penelitian}

1. Debit Air

TABEL 1. DATA DEBIT AIR SUNGAI PER TAHUN

\begin{tabular}{ccc}
\hline No. & Tahun & $\begin{array}{c}\text { Debit Air Rata-rata } \\
\left(\mathrm{m}^{3} / \mathrm{det}\right)\end{array}$ \\
\hline 1. & 2015 & 21,828 \\
2. & 2016 & 42,662 \\
3. & 2017 & 46,618 \\
4. & 2018 & 20,189 \\
5. & 2019 & 19 \\
\multicolumn{2}{l}{ Rata-rata $\left(\mathrm{m}^{3} / \mathrm{det}\right)$} & 30,05 \\
\hline
\end{tabular}

2. Head

TABEL 2. DATA HEAD/TINGI JATUH AIR SUNGAI PER TAHUN

\begin{tabular}{ccc}
\hline No. & Tahun & Rata-rata head air $(\mathrm{m})$ \\
\hline 1. & 2015 & \\
2. & 2016 & 2,17 \\
3. & 2017 & \\
4. & 2018 & \\
5. & 2019 & \\
\hline
\end{tabular}




\section{Pemilihan Jenis Turbin}

Dengan menggunakan grafik pemilihan turbin dibawah, dapat ditentukan turbin yang tepat untuk digunakan pada lokasi rancangan tersebut. Dari grafik tersebut, dapat dilihat untuk lokasi rancangan turbin dengan head air sebesar 2,17 m, dengan debit air sebesar 30,05 m3/det, terdapat lima pilihan turbin yaitu kaplan (daerah kerja turbin ini berada dalam garis berwarna biru), turbin crossflow (daerah kerja turbin ini berada dalam garis berwarna hitam), turbin francis (daerah kerja turbin ini berada dalam garis berwarna kuning), turbin turgo (daerah kerja turbin ini berada dalam garis berwarna hijau) dan turbin pelton (daerah kerja turbin ini berada dalam garis berwarna merah).

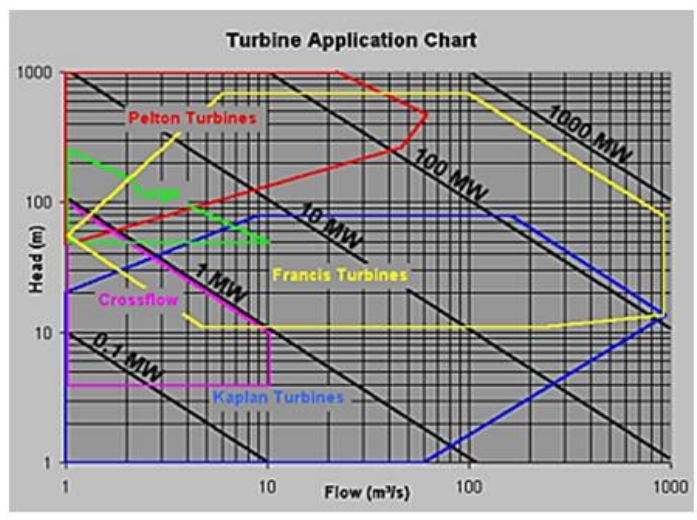

Gambar 1. Grafik Pemilihan Jenis Turbin

Dari kelima turbin tersebut yang dipakai untuk lokasi rancangan PLTMH yaitu turbin kaplan (ditandai dengan tanda titik biru dalam lingkaran garis biru) dipilih dengan alasan kemudahan pengoperasian, biaya yang tidak terlalu mahal dan juga pemilihan berdasarkan perhitungan menggunakan grafik di atas. Turbin kaplan juga dipilih karena sudu pengarah turbin dan sudu gerak turbin bisa diubah agar bisa menyesuaikan kecepatan aliran turbin. Sedangkan pada jenis turbin lain sudu putar/gerak tetap dan tidak berubah.

\section{Potensi Daya Listrik}

\section{a. Perhitungan Secara Manual}

Hubungan daya yang dihasilkan terhadap debit dan tinggi jatuh air dapat dilihat pada persamaan berikut [6]:

$$
\mathbf{P}_{\mathrm{a}}=\boldsymbol{\rho} \eta_{\mathrm{t}} \mathbf{g} \mathbf{Q} \mathbf{H}
$$

TABEL 3. KONSTANTA NILAI POTENSI DAYA LISTRIK

\begin{tabular}{clc}
\hline No. & \multicolumn{1}{c}{ Konstanta } & Nilai \\
\hline 1. & Efisiensi generator $\left(\eta_{\mathrm{g}}\right)$ & $92 \%(0,92)$ \\
2. & Efisiensi turbin $\left(\eta_{\mathrm{t}}\right)$ & $87 \%(0,87)$ \\
3. & Efisiensi total $\eta$ & $0,92 \times 0,87=0,79$ \\
4. & Massa jenis air $(\rho)$ & $1000 \mathrm{~kg} / \mathrm{m}^{3}$ \\
5. & Gravitasi $(\mathrm{g})$ & $9,81 \mathrm{~m} / \mathrm{s}^{2}$ \\
\hline
\end{tabular}

1) Potensi Daya Tahun 2015

$P_{a}(2015)=\rho \cdot \eta \cdot g \cdot Q \cdot H$

$P_{a}(2015)=1000 \cdot 0,79 \cdot 9,81 \cdot 21,82 \cdot 2,17$

$P_{a}(2015)=366953,11 \mathrm{~W}$

$P_{a}(2015)=366,95 \mathrm{~kW}$

2) Potensi Daya Tahun 2016

$$
\begin{aligned}
& P_{a}(2016)=\rho \cdot \eta \cdot g \cdot Q \cdot H \\
& P_{a}(2016)=1000 \cdot 0,79 \cdot 9,81 \cdot 42,66 \cdot 2,17 \\
& P_{a}(2016)=717 \cdot 425,29 \mathrm{~W} \\
& P_{a}(2016)=717,42 \mathrm{~kW}
\end{aligned}
$$

3) Potensi Daya Tahun 2017

$P_{a}(2017)=\rho \cdot \eta \cdot g \cdot Q \cdot H$

$P_{a}(2017)=1000 \cdot 0,79 \cdot 9,81 \cdot 46,61 \cdot 2,17$

$P_{a}(2017)=783.853,56 \mathrm{~W}$

$P_{a}(2017)=783,85 \mathrm{~kW}$

4) Potensi Daya Tahun 2018

$P_{a}(2018)=\rho \cdot \eta \cdot g \cdot Q \cdot H$

$P_{a}(2018)=1000 \cdot 0,79 \cdot 9,81 \cdot 20,18 \cdot 2,17$

$P_{a}(2018)=339.372,77 \mathrm{~W}$

$P_{a}(2018)=339,37 \mathrm{~kW}$

5) Potensi Daya Tahun 2019

$P_{a}(2019)=\rho \cdot \eta \cdot g \cdot Q \cdot H$

$P_{a}(2019)=1000 \cdot 0,79 \cdot 9,81 \cdot 19 \cdot 2,17$

$P_{a}(2019)=319.528,37 \mathrm{~W}$

$P_{a}(2019)=319,52 \mathrm{~kW}$

TABEL 4. REKAPITULASI PERHITUNGAN POTENSI DAYA SECARA MANUAL

\begin{tabular}{ccc}
\hline No. & Tahun & Perhitungan Potensi Daya $(\mathrm{kW})$ \\
\hline 1. & 2015 & 366,95 \\
2. & 2016 & 717,42 \\
3. & 2017 & 783,85 \\
4. & 2018 & 339,37 \\
5. & 2019 & 319,52 \\
Rata-rata $(\mathrm{kW})$ & 505,42 \\
\hline
\end{tabular}

\section{b. Perhitungan Menggunakan Aplikasi Hydropower Casimir}

TABEL 5. DATA MASUKAN MENGGUNAKAN APLIKASI HYDROPOWER CASIMIR

\begin{tabular}{ll}
\hline \multicolumn{2}{c}{ PLTMH } \\
\hline Aliran Minimum & $0,3 \mathrm{~m}^{3} / \mathrm{s}$ \\
Efisiensi Total & 0,79 \\
Debit minimum turbin & $1 \mathrm{~m}^{3} / \mathrm{s}$ \\
Debit maksimum turbin & $50 \mathrm{~m}^{3} / \mathrm{s}$ \\
Debit maksimum bak & $100 \mathrm{~m}^{3} / \mathrm{s}$ \\
penenang & \\
\hline
\end{tabular}


1) Potensi daya Tahun 2015

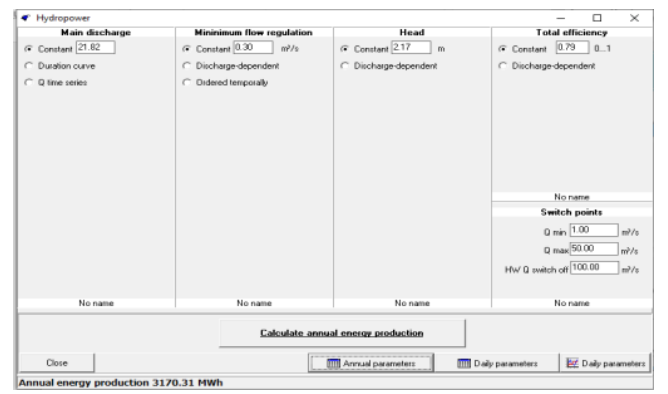

Gambar 2. Data Masukan Aplikasi Hydropower Casimir

Gambar 3. Parameter Tahun 2015 Menggunakan

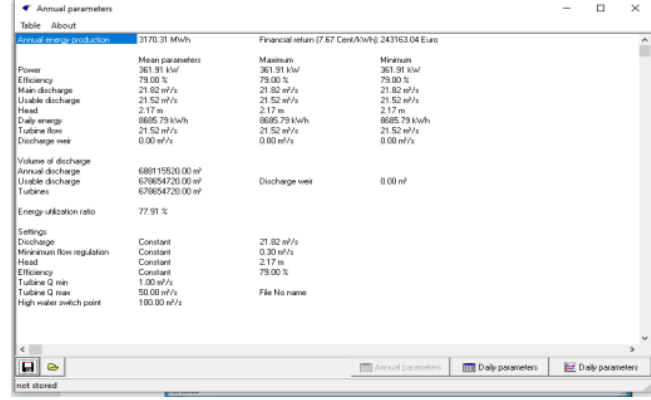

Aplikasi Hydropower Casimir

2) Potensi Daya Tahun 2016

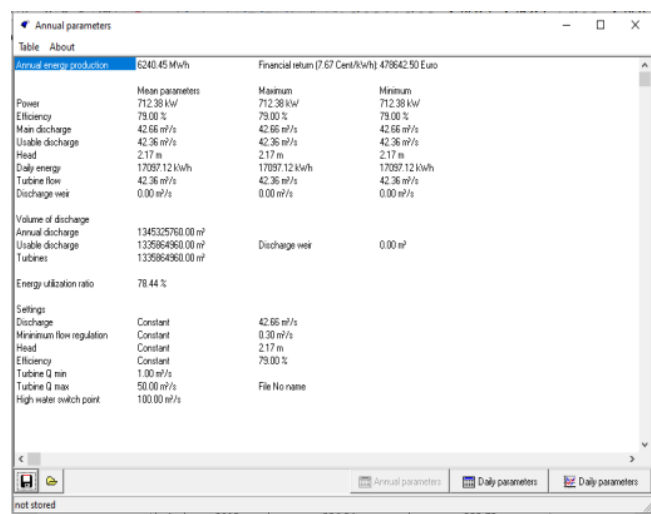

Gambar 4. Parameter Tahun 2016 Menggunakan Aplikasi Hydropower Casimir

3) Potensi Daya Tahun 2017

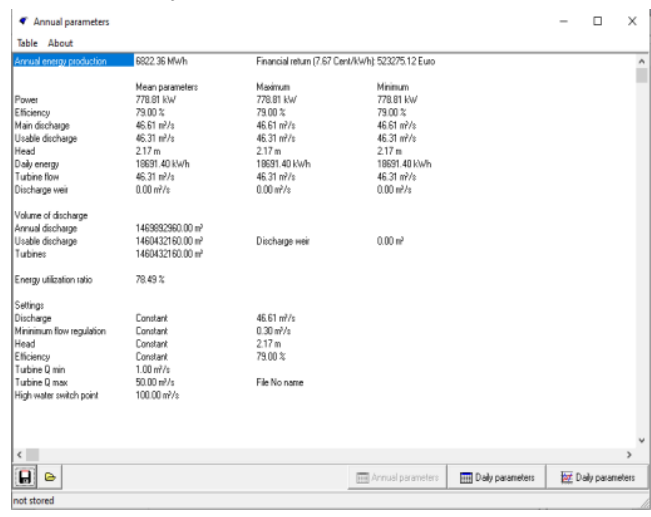

Gambar 5. Parameter Tahun 2017 Menggunakan Aplikasi Hydropower Casimir
4) Potensi Daya Tahun 2018

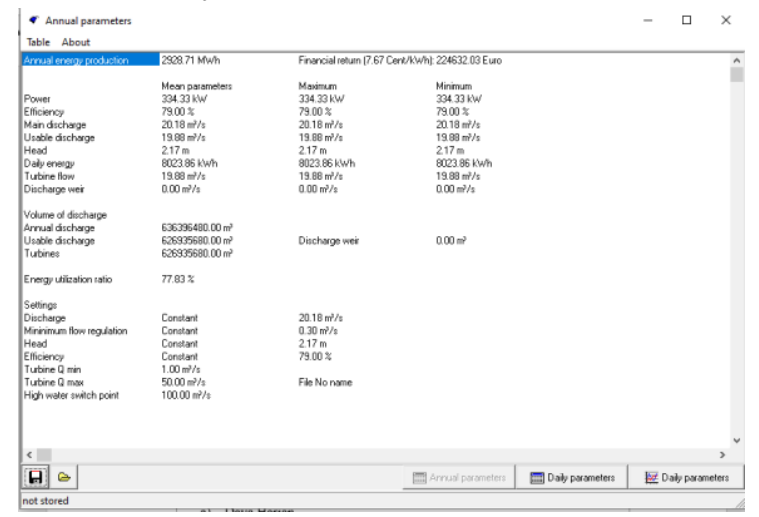

Gambar 6. Parameter Tahun 2018 Menggunakan Aplikasi Hydropower Casimir

5) Potensi Daya Tahun 2019

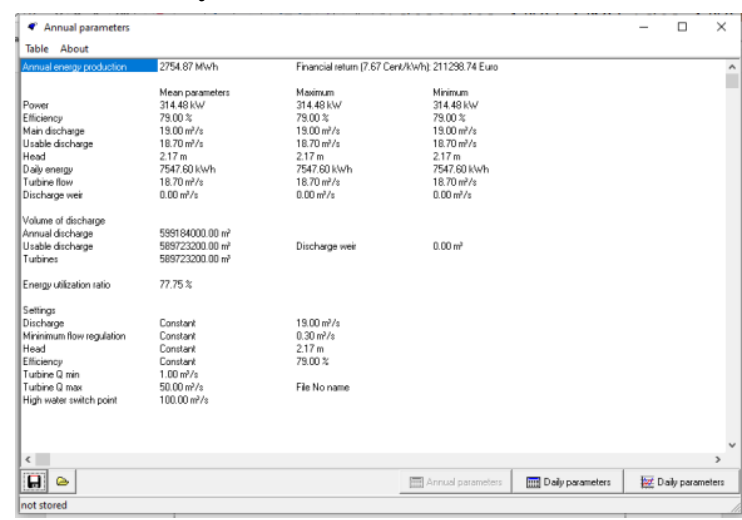

Gambar 7. Parameter Tahun 2019 Menggunakan Aplikasi Hydropower Casimir

TABEL 6. REKAPITULASI PERHITUNGAN POTENSI DAYA

\begin{tabular}{ccc}
\hline No. & Tahun & Perhitungan Potensi Daya $(\mathrm{kW})$ \\
\hline 1. & 2015 & 361,91 \\
2. & 2016 & 712,38 \\
3. & 2017 & 778,81 \\
4. & 2018 & 334,33 \\
5. & 2019 & 314,48 \\
Rata-rata $(\mathrm{kW})$ & 500,38 \\
\hline
\end{tabular}

\section{B. Pembahasan}

Pada 5 tahun terakhir yaitu rentang waktu dari tahun 2015 sampai 2019, terjadi kenaikan debit air sungai Noling pada tahun 2016 dari tahun 2015. Akan tetapi terjadi penurunan debit air sungai Noling pada tahun 2017, 2018 dan 2019. Beberapa faktor yang mempengaruhi terjadi kenaikan dan penurunan debit air sungai Noling diantaranya; 1) curah hujan, 2) tekstur tanah, 3) kemiringan lereng, 4) kerapatan sungai, 5) tutupan lahan.

Berdasarkan data debit air dan head/jatuh air Sungai Noling tersebut maka jenis turbin yang cocok dan sesuai adalah jenis turbin Kaplan, karena sesuai dengan kriteria data-data pada sungai Noling dan 
grafik pemilihan jenis turbin. Dimana untuk jenis turbin kaplan, debit airnya antara $1 \mathrm{~m} 3 / \mathrm{s}$ sampai dengan $1000 \mathrm{~m} 3 / \mathrm{s}$ sedangkan untuk head/jatuh air antara $1 \mathrm{~m}$ sampai dengan $100 \mathrm{~m}$.

Sungai Noling memiliki potensi besar untuk dimanfaatkan sebagai sumber energi menjadi Pembangkit Listrik Tenaga Mikro Hidro. Berdasarkan analisis data debit air dan head/jatuh air 5 tahun terakhir rentang tahun 2015-2019, dengan debit air rata-rata bervariasi adalah Q2015 $=21,82 \mathrm{~m} 3 / \mathrm{s}, \mathrm{Q} 2016=41,62 \mathrm{~m} 3 / \mathrm{s}, \mathrm{Q} 2017=46,61$ $\mathrm{m} 3 / \mathrm{s}, \mathrm{Q} 2018=20,18 \mathrm{~m} 3 / \mathrm{s}, \mathrm{Q} 2019=19 \mathrm{~m} 3 / \mathrm{s}$ dan $\mathrm{H}($ konstan $)=2,17 \mathrm{~m}$, maka dapat dihitung potensi daya listrik tahunan dengan menggunakan aplikasi hydropower casimir bisa dibangkitkan listrik adalah P2015 $=361,91 \mathrm{~kW}, \mathrm{P} 2016=712,38 \mathrm{~kW}$, P2017 = 778,81 kW, P2018 = 334,33 kW, P2019 $=314,48 \mathrm{~kW}$. Sedangkan rekapitulasi potensi daya listrik rata-rata 5 tahun terakhir rentang tahun 2015-2019, dengan menggunakan aplikasi hydropower casimir yang bisa dibangkitkan adalah sebesar 500,38 kW.

\section{SIMPULAN}

1. Sungai Noling memiliki debit air rata-rata 5 tahun terakhir rentang tahun 2015-2019, yakni sebesar $\mathrm{Q}_{2015}=21,82 \mathrm{~m}^{3} / \mathrm{s}, \mathrm{Q}_{2016}=$ $41,62 \mathrm{~m}^{3} / \mathrm{s}, \mathrm{Q}_{2017}=46,61 \mathrm{~m}^{3} / \mathrm{s}, \mathrm{Q}_{2018}=20,18$ $\mathrm{m}^{3} / \mathrm{s}, \mathrm{Q}_{2019}=19 \mathrm{~m}^{3} / \mathrm{s}$ dan $\mathrm{H}$ (konstan) $=2,17$ $\mathrm{m}$.

2. Turbin air yang digunakan untuk Pembangkit Listrik Tenaga Mikro Hidro di Sungai Noling Kelurahan Noling Kabupaten Luwu adalah jenis turbin kaplan. Turbin kaplan dipilih karena mampu beroperasi pada head/jatuh air yang rendah dengan rentang $1 \mathrm{~m}$ sampai 100 $\mathrm{m}$ dan debit air yang kecil dan besar dengan rentang $1 \mathrm{~m}^{3} / \mathrm{s}$ sampai $1000 \mathrm{~m}^{3} / \mathrm{s}$.

3. Potensi Daya Listrik Sungai Noling sebagai sumber energi Pembangkit Listrik Tenaga Mikro Hidro per tahun sebesar $\mathrm{P}_{2015}=361,91$ $\mathrm{kW}, \mathrm{P}_{2016}=712,38 \mathrm{~kW}, \mathrm{P}_{2017}=778,81 \mathrm{~kW}$, $\mathrm{P}_{2018}=334,33 \mathrm{~kW}, \mathrm{P}_{2019}=314,48 \mathrm{~kW}$ dan rekapitulasi data rata-rata 5 tahun terakhir rentang tahun 2015-2019 adalah sebesar $500,38 \mathrm{~kW}$.

\section{DAFTAR PUSTAKA}

[1] H. Candra, "Tinjauan Yuridis Mengenai Penerapan Undang-Undang Nomor 30 Tahun 2009 Tentang Ketenagalistrikan Terhadap Penyediaan Tenaga Listrik Dan Pengelolaan Iuran Listrik Rumah Susun Di Indonesia (Studi Kasus Terhadap Tiga Apartemen Di Jakarta)," Jurnal Hukum dan Bisnis (Selisik), vol. 4, no. 2, pp. 22-41, 2018.

[2] R. Indonesia, "Peraturan Pemerintah No. 79 Tahun 2014 tentang Kebijakan Energi Nasional," Lembaran Negara RI Tahun, no. 300, 2014.

[3] A. Gunawan, A. Oktafeni, and W. Khabzli, "Pemantauan pembangkit listrik tenaga mikrohidro (PLTMH)," Jurnal rekayasa elektrika, vol. 10, no. 4, pp. 201-206, 2013.

[4] C. Asdak, Hidrologi dan pengelolaan daerah aliran sungai. Gadjah Mada University Press, 2018.

[5] Sugiono, Metode Penelitian Kuantitatif Kualitatif dan $R \& D$. Bandung: Alfabeta, 2008.

[6] V. Dwiyanto, D. I. Kusumastuti, and S. Tugiono, "Analisis Pembangkit Listrik Tenaga Mikro Hidro (PLTMH) Studi Kasus: Sungai Air Anak (Hulu Sungai Way Besai)," Jurnal Rekayasa Sipil dan Desain, vol. 4, no. 3, pp. 407-422, 2016. 